\title{
Effect of STAT5 silenced by siRNA on proliferation apoptosis and invasion of esophageal carcinoma cell line Eca-109
}

Qian Yang ${ }^{1}$, Min $\mathrm{Li}^{2}$, Tao Wang ${ }^{3}$, Hong Xu ${ }^{4}$, Wenqiao Zang ${ }^{2^{*}}$ and Guoqiang Zhao ${ }^{2^{*}}$

\begin{abstract}
Background: STAT is the backward position of cytokine and growth factor receptors in the nucleus, STAT dimers could bind to DNA and induce transcription of specific target genes. Several lines of evidence support the important roles of STAT, especially STAT5, in carcinogenesis. The overexpression of STAT 5 is related to the differentiation and apoptosis of tumor cells. However, the role of STAT5 in esophageal squamous cell carcinoma remains unclear.

Methods: The siRNA vectors aiming to STAT5 gene were constructed. STAT5 siRNA was transfected into Eca-109 cells by Lipofectamine ${ }^{\text {TM}} 2000$. Expression of STAT5、BCl-2 and Cyclin D1 were analyzed by Western blot and RT-PCR. Eca-109 cells proliferation was determined by MTT. Eca-109 cell cycle and apoptosis were detected by the flow cytometry. Boyden chamber was used to evaluate the invasion and metastasis capabilities of Eca-109 cells.

Results: The double strands oligonucleotide of siRNA aiming to STAT5 was successfully cloned into the pRNAT-U6.1 vector, and the target sequence coincided with the design. RT-PCR and Western blotting detection demonstrated that the expression levels of STAT5、BCl-2 and Cyclin D1 gene were obviously decreased in Eca-109 cells transfected with STAT5 siRNA. STAT5 siRNA could suppress the proliferation of Eca-109 cells. The proportion of S and G2/M period frequency was significantly decreased $(p<0.05)$. The proportion of G0/G1 period frequency was significantly increased $(p<0.05)$. The average amount of cells penetrating Matrigel was significantly decreased $(p<0.05)$.

Conclusions: STAT5 silenced by siRNA could induce the apoptosis and suppress the proliferation、 invasion and metastasis of esophageal carcinoma cell line Eca-109, which indicated STAT5 might be a novel therapeutic strategy for the human ESCC.

Virtual slides: The virtual slide(s) for this article can be found here: http://www.diagnosticpathology.diagnomx.eu/vs/ 1351913072103000
\end{abstract}

Keywords: STAT5, siRNA, Proliferation, Cell cycle, Apoptosis

\section{Introduction}

The STAT (signal transducer and activator of transcription) family of proteins includes 7 members (STAT -1 、 2、3、4、5a, $5 \mathrm{~b}$ and 6 ) encoded by distinct genes in mammalian cells. The STAT family members are latent cytoplasmic transcription factors that are activated in response to extracellular signaling proteins, including growth factors, cytokines, hormones, and peptides [1-5]. STAT is the backward position of cytokine and growth

\footnotetext{
*Correspondence: zangwenqiao@sina.com; zhaogq@126.com

${ }^{2}$ College of Basic Medical Sciences, Zhengzhou University, Zhengzhou,

People's Republic of China

Full list of author information is available at the end of the article
}

factor receptors in the nucleus, STAT dimers bind to DNA and induce transcription of specific target genes [6-9]. The overexpression of STAT 5 is related to the differentiation, apoptosis and new capillaries of tumor cells [10-14]. In this study, We silenced STAT5 by siRNA to explore the effect on proliferation 、apoptosis and invasion of esophageal carcinoma cell line Eca-109, which gave a certain target in gene therapy of Esophageal Carcinoma.

\section{Materials and methods \\ Main materials \\ siRNA vectors pRNAT-U6.1/Neo (GeneScript Corp, China); BamHI 、HindIII and T4 DNA ligase(Promega}

\section{Biomed Central}


Corp, USA); the first antibody of STAT5, Bcl-2, Cyclin D1,GAPDH(Santa Cruz Corp, USA); RPMI 1640; LipofectAmine $^{\mathrm{mw}} 2000$, G418(Invitrogen, USA); MTT、 DMSO、Trypsin、PI、RNAase(Sigma Corp, USA); Esophageal carcinoma cell line Eca-109 were obtained from the basic medical college of Zhengzhou University.

\section{Design the STAT5 gene target oligonucleotide}

Abide by the principle of design siRNA fragment and the target oligonucleotide was designed with the help of the GenScript siRNA Target Finder software of GenScript company, which the following web address provided: https://www.genscript.com/ssl-bin/app/rnai The target sequences located in 2851nt-2869nt (GGCAGTGAGTTTC GTGAAG).

\section{The construction of siRNA vectors}

Two couples of hairpin sample DNA oligonycleotides (2851-1、2851-2 and Con-1、Con-2)were annealed to produce dsDNA(siSTAT5 and siCon). Then the dsDNA was inserted into the BgIII and HindIII site of thepRNATU6.1/Neo vector. $2 \times$ reaction buffer $5 \mu \mathrm{L}$, sticking end linear pRNAT-U6.1 /Neo vectors $1 \mu \mathrm{L}$, T4 DNA ligase $1 \mu \mathrm{L}$, dsDNA(siSTAT5 and siCon) $3 \mu \mathrm{L}$, All of them were for a whole night at $4^{\circ} \mathrm{C}$. The recombinant vectors were transformed into Escherichia coli DH5 $\alpha$. The pRNATU6.1/Neo-siSTAT5 and pRNAT-U6.1/Neo-siCon vectors were constructed after the analyzsis of consequense.

\section{The transfection of Eca-109 cells with} Lipofectamine $^{\mathrm{TM}} 2000$

When the density of plasmids was $2 \mu \mathrm{g} / \mathrm{ml}$, the pRNATU6.1/Neo-siSTAT5 and pRNAT-U6.1/Neo-siCon were transfected into Eca-109 cells, as the experiment group and the siRNA control group. According to the manufacturer's protocol of Lipofectamine ${ }^{\mathrm{Tx}} 2000$, and the cells were cultured after $6 \mathrm{~h}$. The experiments were performed independently four times.

\section{RT-PCR}

The GAPDH was used as the internal reference, then the primers and probes were designed according to the software of Primer Express 3.0(ABI Corp), which all are synthetized by Shanghai bioengineering company (Table 1). Total RNA was isolated from the cells using Trizol extraction kit according to the manufacturer's protocol. RT-PCR was performed with the apparatus of ABI Step One Plus PCR. The ratio of the copies of the detected genes (STAT5、Bcl-2、Cyclin D1)to the copies of GAPDH was the relative expression quantity. The experiments were performed independently four times.

\section{Western blot}

Cells were lysed for total protein extraction. The protein concentration was determined by the BCA method (KeyGEN, China), and $30 \mu \mathrm{g}$ of protein lysates were subjected to SDS-PAGE. The electrophoresed proteins were transferred to nitrocellulose membranes (Whatman, USA), which were blocked in 5\% non-fat milk and incubated overnight at $4{ }^{\circ} \mathrm{C}$ with diluted first antibodies. Membranes were then incubated with HRP-conjugated secondary antibody (1:2,500, Santa Cruz, USA). After washing with PBST buffer (PBS containing 0.05\% Tween-20), membranes were probed using ultra-enhanced chemiluminescence western blotting detection reagents. GAPDH was used as the internal reference.

\section{MTT assay}

The experimental groups of cells in the logarithmic phase of growth were seeded in 96-well plates at a cell

Table 1 RT-PCR probes

\begin{tabular}{|c|c|c|}
\hline Names & Probes & Sequence \\
\hline \multirow[t]{3}{*}{ STAT5 } & Forward Primer & 5' GCTGGAAGCCTTGCTGAT 3' \\
\hline & Reverse Primer & 5' TCCTCAAACGTCTGGTTGATC 3' \\
\hline & Probe & 5' FAM-TGTCCCAGAAACACCTC-TAMRA 3' \\
\hline \multirow[t]{3}{*}{$\mathrm{BC} 12$} & Forward Primer & 5' CATGTGTGTGGAGAGCGTCAA 3' \\
\hline & Reverse Primer & 5' GCCGGTTCAGGTACTCAGTCAT 3' \\
\hline & Probe & 5' FAM-TGGACAACATCGCCCTGT-TAMRA 3' \\
\hline \multirow[t]{3}{*}{ Cyclin-D1 } & Forward Primer & 5' GTGGCCTCTAAGATGAAGGA 3' \\
\hline & Reverse Primer & 5' GGTGTAGATGCACAGCTTCT 3' \\
\hline & Probe & 5' FAM-ACCATCCCCCTGACGGC-TAMRA 3' \\
\hline \multirow[t]{3}{*}{ GAPDH } & Forward Primer & 5' GGTGGTCTCCTCTGACTTCAACA 3' \\
\hline & Reverse Primer & 5' CCAAATTCGTTGTCATACCAGGAAATG 3' \\
\hline & Probe & 5'FAM-CGACACCCACTCCTCCACCTITGACGC-TAMRA 3' \\
\hline
\end{tabular}


density of $0.4 \times 10^{4} /$ well. For six consecutive days, $20 \mu \mathrm{l}$ of MTT $(5 \mathrm{mg} / \mathrm{ml})$ was added to the corresponding well, cells were incubated at $37^{\circ} \mathrm{C}$ for an additional $4 \mathrm{~h}$, and the reaction was stopped by lysing the cells with $200 \mu \mathrm{l}$ of DMSO for $20 \mathrm{~min}$. Optical density was measured at $590 \mathrm{~nm}$ The experiments were performed independently four times.

\section{The flow cytometry detects the cell cycle}

For cell cycle analysis by flow cytometry (FCM), cells in the logarithmic phase of growth were harvested by trypsinization, washed with PBS, fixed with $75 \%$ ethanol overnight at $4{ }^{\circ} \mathrm{C}$ and incubated with RNase at $37^{\circ} \mathrm{C}$ for $30 \mathrm{~min}$. Nuclei were stained with propidium iodide for $30 \mathrm{~min}$. A total of $10^{4}$ nuclei were examined in a FACSCalibur Flow Cytometer (Becton Dickinson, Franklin Lakes, NJ, USA). The experiments were performed independently four times.

\section{Cell apoptosis assay}

Every group cells were harvested and diluted with PBS twice. Then $5 \mu \mathrm{L}$ of FITC-labeled enhanced-annexinV and $5 \mu \mathrm{l} 20 \mu \mathrm{g} / \mathrm{ml}$ of propidium iodide were added to $100 \mu \mathrm{l}$ cell . Upon incubation in the dark for $15 \mathrm{~min}$ at room temperature, samples were diluted with $400 \mu \mathrm{l}$ PBS. Flow cytometry was carried out on a FACS can instrument. The result was analysed by random software. The experiments were performed independently four times.

\section{Cell invasion assay}

The invasion ability of Eca-109 cells was assayed using Transwells $(8-\mu \mathrm{m}$ pore size, Corning Costar Corp). Transwells filters were coated with matrigel $(3.9 \mu \mathrm{g} / \mu \mathrm{l}$, 60-80 $\mu \mathrm{l}$ ) on the upper surface of the polycarbonic membrane ( $6.5 \mathrm{~mm}$ in diameter, $8 \mu \mathrm{m}$ pore size). Eca-109 cells $\left(3 \times 10^{5}\right)$ treated with 1640 medium without FBS were plated to the upper chamber. 1640 medium with the supernatant of NIH3T3 cells as chemoattractants were plated in the lower chamber of the 24-well pates. After incubation for $24 \mathrm{~h}$, noninvading cells were removed mechanically from the upper chamber using a cotton swab. Cells that invaded to the lower surface of the transwell membrane were fixed in methanol for $30 \mathrm{~min}$ at $37^{\circ} \mathrm{C}$ and stained with $0.05 \%$ crystal violet for $1 \mathrm{~h}$. Cells were quantified by counting the number of stained cells in five individual fields by microscopy. The experiments were performed independently four times.

\section{Statistical analysis}

SPSS17.0 was used for statistical analysis. One-way analysis of variance (ANOVA) and the $\chi^{2}$ test were used to analyze the significance between groups. Multiple comparisons between the parental and control vector groups were made using the Least Significant Difference test when the probability for ANOVA was statistically significant. All data represent mean \pm SD. Statistical significance was set at $p<0.05$.

\section{Results}

STAT5 siRNA inhibited significantly the mRNA and protein expression of STAT5、BCl-2 and Cyclin D1

The result of RT-PCR was in the Table 1. The STAT5、 Bcl-2 and Cyclin D1 mRNA expression in untransfected Eca-109 cells were coincident with that in the cells transfected with control vector( pRNAT-U6.1/Neo-siCon). The statistical data between them was not significance $(\mathrm{p}>0.05)$. RT-PCR results showed that STAT5、Bcl-2 and Cyclin D1 mRNA expression in STAT5 siRNA group were significantly inhibited compared to siRNA control and blank control group as shown in Table 2. The targeted STAT5 siRNA inhibited significantly the mRNA expression of STAT5 gene. The results of Western-Blot showed the expression of STAT5 protein was significantly decreased in Eca-109 cells in STAT5 siRNA group (Figure 1A). The result showed that the Bcl-2 and Cyclin D1 expression in Eca-109 cells transfected with STAT5 siRNA vector were significantly decreased.

\section{STAT5 siRNA inhibited esophageal carcinoma cells proliferation in vitro}

Compared with untransfected cells and cells transfected with control vector, the Eca-109 cell transfected with vector (pRNAT-U6.1/Neo-siSTAT5) were significantly depressed respectively at $24 \mathrm{~h} 、 48 \mathrm{~h}$ and $72 \mathrm{~h}$. The cells become round at $24 \mathrm{~h}$. With the longer time, the smaller shed cells become more and more. The result showed that silencing the STAT5 depresses the proliferation of esophageal carcinoma cell line Eca-109 (Figure 1B).

\section{STAT5 siRNA affect the cell cycle of Eca-109 cells}

Compared with untransfected Eca-109 cells and cells transfected with control vector, The proportion of $S$ and G2/M period frequency of Eca-109 cell transfected with vetor (pRNAT-U6.1/Neo-siSTAT5) was significantly de$\operatorname{creased}(p<0.05)$. The proportion of $\mathrm{G} 0 / \mathrm{G} 1$ period

Table 2 STAT5 siRNA inhibited significantly the mRNA expression of STAT5、Bcl-2 and Cyclin D1

\begin{tabular}{lclll}
\hline Group & $\mathbf{n}$ & STAT5/GAPDH & Bcl-2/GAPDH & Cyclin D1/GAPDH \\
\hline STAT5 siRNA & 4 & $0.301 \pm 0.012^{*}$ & $0.266 \pm 0.012^{*}$ & $0.048 \pm 0.005^{*}$ \\
siRNA control & 4 & $0.836 \pm 0.038$ & $0.645 \pm 0.023$ & $0.261 \pm 0.013$ \\
$\begin{array}{l}\text { The blank } \\
\text { control }\end{array}$ & 4 & $0.857 \pm 0.041$ & $0.687 \pm 0.027$ & $0.273 \pm 0.012$
\end{tabular}

Cells were incubated with different synthetic oligonucleotides as described in the materials and methods section, and STAT5、Bcl-2 and Cyclin D1mRNA were quantified by real time PCR. The targeted STAT5 siRNA inhibited significantly the expression of STAT5、Bcl-2 and Cyclin D1 gene ( $\left.{ }^{*} \mathrm{p}<0.05\right)$. 

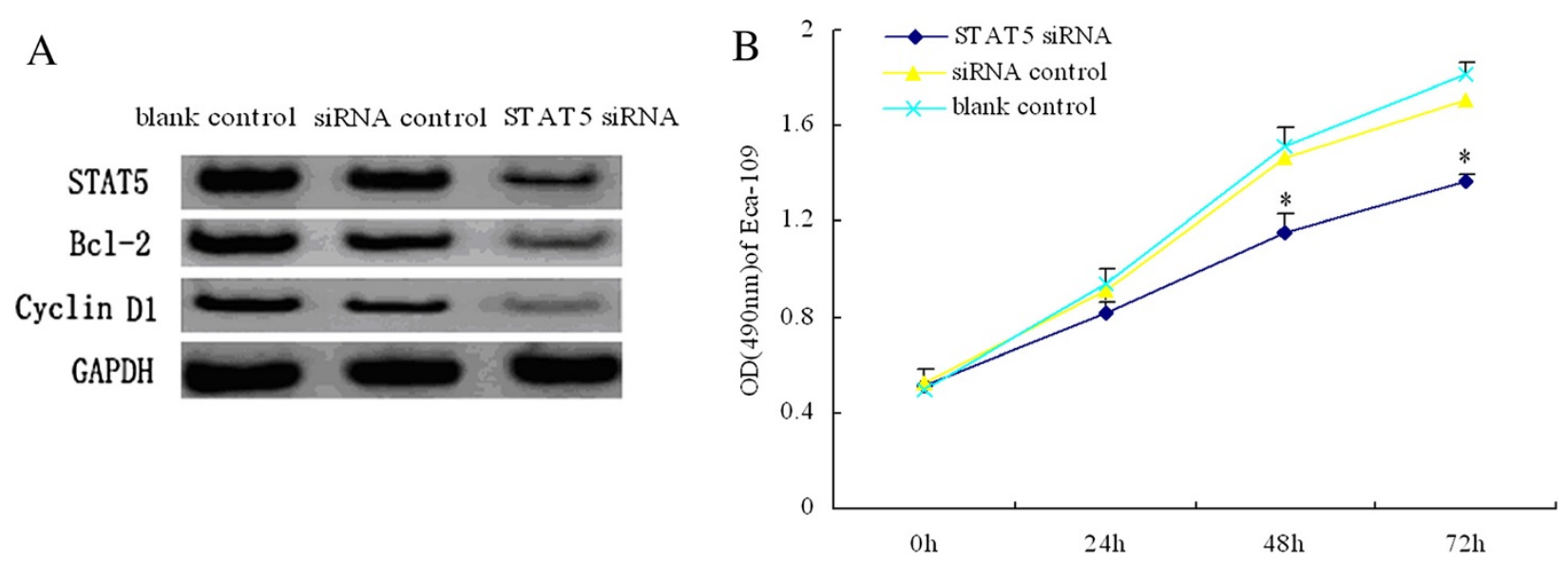

Figure 1 The results of protein expression and cell proliferation. A STAT5 siRNA inhibited significantly the protein expression of STAT5、BCl-2 and Cyclin D1. Cells were incubated with different synthetic oligonucleotides as described in the materials and methods section, and CXCR4 protein was quantified by Western-Blot. The targeted CXCR4 siRNA inhibited significantly the protein expression of STAT5、BCl-2 and Cyclin D1 gene. B cell proliferation was assessed using the MTT assay. Data are presented as the mean of four experiments. Silencing the STAT5 depresses the proliferation of esophageal carcinoma cell line Eca-109. Significant difference $(p<0.05)$.

frequency was significantly increased $(p<0.05)$ as shown in Table 3.

\section{STAT5 siRNA induced the apoptosis and suppressed invasion and metastasis of Eca-109}

Compared with untransfected Eca-109 cells and cells transfected with conrtrol vector, The average apoptosis rate of Eca-109 cell transfected with vector (pRNAT-U6.1/NeosiSTAT5) was significantly increased $(p<0.05)$, The average amount of cells penetrating matrigel was significantly de$\operatorname{creased}(p<0.05)$. The result showed that silencing the STAT5 induced the apoptosis and suppressed invasion and metastasis of esophageal carcinoma cell line Eca-109 as shown in Table 4.

\section{Discussion}

The activation of JAK phosphorylates STAT proteins, leading to their dimerization and translocation into the nucleus [15]. In the nucleus, STATs act as transcription factors with pleiotropic downstream effects. STATs are phosphorylated on tyrosine residues via JAK kinases and on serine residues by a variety of serine/threonine kinases [16]. STATs then

Table 3 STAT5 siRNA affect the cell cycle of Eca-109 cells

\begin{tabular}{lccc}
\hline Group & $\mathbf{G}_{\mathbf{0}} \sim \mathbf{G}_{\mathbf{1}}(\%)$ & $\mathbf{S}(\%)$ & $\mathbf{G}_{\mathbf{2}} \sim \mathbf{M}(\%)$ \\
\hline STAT5 siRNA & $75.9 \pm 2.3$ & $20.85 \pm 0.55^{*}$ & $3.25 \pm 0.12^{*}$ \\
siRNA control & $64.23 \pm 1.92$ & $27.8 \pm 0.61$ & $7.96 \pm 0.27$ \\
The blank control & $64.69 \pm 2.16$ & $26.46 \pm 0.59$ & $8.85 \pm 0.31$
\end{tabular}

The cell cycle was detected by flow cytometry. The proportion of $\mathrm{S}$ and G2/M period frequency of Eca-109 cell transfected with vetor (pRNAT-U6.1/Neo-siSTAT5) was significantly decreased $\left({ }^{*} p<0.05\right)$. The proportion of G0/G1 period frequency was significantly increased $\left({ }^{*} p<0.05\right)$. dimerize, translocate to the nucleus and bind DNA, initiating the transcription of target genes. STAT proteins mediate cell growth, differentiation, apoptosis, transformation, and other functions. In cancer cells, STAT5 activation lead to the increased expression of downstream target genes (Bcl-xL, mcL-1, cyclinD1 /D2 and c-myc), which increased cell proliferation, cell survival, angiogenesis, and immune system evasion [17]. STAT5 is very mportant in STATs family, including STAT5a and STAT5b, which plays an important role in many cancers [18].

The study designed and constructed the siRNA vector (pRNAT-U6.1/Neo -siSTAT5) aiming to STAT5. Then it was transfected into Eca-109 cells. The result of RT-PCR and Western-blot demonstrated STAT5 was significantly suppressed, not only the mRNA expression, but also the protein expression, The $\mathrm{Bcl}-2$ and Cyclin D1 expression in Eca-109 cells transfected with STAT5 siRNA vector were significantly decreased. The result of MTT demonstrated the cell growth was significantly suppressed. The

Table 4 STAT5 siRNA induced the apoptosis and suppressed invasion and metastasis of Eca-109

\begin{tabular}{lccc}
\hline Group & $\begin{array}{c}\text { Transfected } \\
\text { vector }\end{array}$ & $\begin{array}{c}\text { The cell apoptosis } \\
\text { rate (\%) }\end{array}$ & $\begin{array}{c}\text { The average amount } \\
\text { of cells per field }\end{array}$ \\
\hline STAT5 siRNA & $\begin{array}{c}\text { pRNAT-U6.1/ } \\
\text { Neo -siSTAT5 }\end{array}$ & $13.38 \pm 1.87^{*}$ & $24.2 \pm 5.1^{*}$ \\
siRNA control & $\begin{array}{c}\text { pRNAT-U6.1/ } \\
\text { Neo-siCon }\end{array}$ & $4.76 \pm 0.69$ & $65.2 \pm 10.4$ \\
The blank & - & $4.49 \pm 0.73$ & $71.9 \pm 12.4$ \\
control & & & \\
\hline
\end{tabular}

The average apoptosis rate of Eca-109 cell transfected with STAT5 siRNA was significantly increased $\left({ }^{*} p<0.05\right)$, The average amount of cells penetrating Matrigel was significantly suppressed $(* p<0.05)$. 
result of flow cytometry demonstrated the proportion of $\mathrm{S}$ and $\mathrm{G} 2 / \mathrm{M}$ period frequency was significantly decreased $(p<0.05)$. The proportion of G0/G1 period frequency was significantly increased $(p<0.05)$. Zhao Zhengjun e.tal approved silencing the STAT5 of liver carcinoma cell SMMC27721 induced the cell apoptosis, using siRNA [19]. Duan zhao e.tal approved silencing the STAT5 depressed the proliferation of cervical carcinoma cell HeLa and induced the cell apoptosis [20]. The proportion of S and G2/M period frequency was significantly decreased. The proportion of G0/G1 period frequency was significantly increased. All are associated with our study. There are other risk factors associated with esophageal carcinomas. Fascin induces membrane protrusions and cell motility [21]. Fascin overexpression plays a role in tumor growth and progression in ESCC and that cell death caused by its downregulation might be induced by cell adhesion loss [22]. This indicates that targeting fascin pathway could be a novel therapeutic strategy for the human ESCC. ATP-binding cassette subfamily $G$ member 2 (ABCG2) is a protein that in humans is encoded by the ABCG2 gene. ABCG2 participates in efflux of many chemotherapeutic agents [23]. ABCG2 is often expressed in hematopoietic progenitor or stem cells. Vacuolar-H +-ATPase (V-ATPase) plays a key role in adjusting and maintaining intracellular $\mathrm{pH}$ and in regulating the drug tolerance of cells [24]. Both ABCG2 and V-ATPase were over-expressed in esophageal squamous cancer cells. Their expression was associated with pathological grade, TNM stage and tumor metastasis in esophageal squamous cancer cells [25]. ABCG2 and V-ATPase expression may be strongly associated with drug resistance and tumor metastasis. All the risk factors were very important in the occurrence and development of esophageal carcinomas.

The study first approved silencing the STAT5 of esophageal carcinoma cell line Eca-109 induced the apoptosis and supressed the proliferation,invasion and metastasis, which indicated STAT5 might be a novel therapeutic strategy for the human ESCC.

\section{Conclusions}

STAT5 silenced by siRNA could induce the apoptosis, suppress the proliferation、 invasion and metastasis of esophageal carcinoma cell line Eca-109, which indicated STAT5 might be a novel therapeutic strategy for the human ESCC.

\section{Competing interests}

The authors declare that they have no competing interests.

\section{Authors' contribution}

QY, ML and HX: conceived of the study, and participated in its design and coordination and helped to draft the manuscript. WQZ and GQZ: carried out part of experiments and wrote the manuscript. LPP and TW performed the statistical analysis. All authors read and approved the final manuscript.

\section{Author details}

'Medical Examination Center, The First Affiliated Hospital of Henan University of TCM, Zhengzhou, People's Republic of China. ${ }^{2}$ College of Basic Medical Sciences, Zhengzhou University, Zhengzhou, People's Republic of China. ${ }^{3}$ Department of Hemato-tumor, The First Affiliated Hospital of Henan University of TCM, Zhengzhou, People's Republic of China. ${ }^{4}$ Henan Tumor Institute, Zhengzhou, People's Republic of China.

Received: 6 July 2013 Accepted: 23 July 2013

Published: 5 August 2013

\section{References}

1. Haro A, Yano T, Yoshida T, et al: Results of a surgical resection of pulmonary metastasis from malignant head and neck tumor. Interact Cardiovasc Thorac Surg 2010, 10(5):700-703.

2. Takemoto S, Ushijima K, Kawano K, et al: Expression of activated signal transducer and activator of transcription-3 predicts poor prognosis in cervical squamous-cell carcinoma. Br J Cancer 2009, 101(6):967-972.

3. Halupa A, Bailey ML, Huang K, Iscove NN, Levy DE, Barber DL: A novel role for STAT1 in regulating murine erythropoiesis: deletion of STAT1 results in overall reduction of erythroid progenitors and alters their distribution. Blood 2005, 105:552-561.

4. Isaksen DE, Baumann H, Trobridge PA, Farr AG, Levin SD, Ziegler SF: Requirement for stat5 in thymic stromal lymphopoietin-mediated signal transduction. Immunol 1999, 163:5971-5977.

5. Buettner R, Mora LB, Jove R: Activated STAT signaling in human tumors provides novel molecular targets for therapeutic intervention. Clin Cancer Res 2002, 8:945-954.

6. Sillaber C, Gesbert F, Frank DA, Sattler M, Griffin JD: STAT5 activation contributes to growth and viability in Bcr/Abl-transformed cells. Blood 2000, 95:2118-2125.

7. Walker SR, Nelson EA, Frank DA: STAT5 represses BCL6 expression by binding to a regulatory region frequently mutated in lymphomas. Oncogene 2007, 26:224-233.

8. Farrar MA: Design and use of constitutively active STAT5 constructs. Methods Enzymol 2010, 485:583-596.

9. Yao Z, Cui Y, Watford WT, Bream JH, Yamaoka K, Hissong BD, Li D, Durum SK, Jiang $Q$, Bhandoola A, et al: Stat5a/b are essential for normal lymphoid development and differentiation. Proc Natl Acad Sci U S A 2006, 103:1000-1005.

10. Hoelbl A, Kovacic B, Kerenyi MA, Simma O, Warsch W, Cui Y, Beug H, Hennighausen L, Moriggl R, Sexl V: Clarifying the role of Stat5 in lymphoid development and Abelson-induced transformation. Blood 2006, 107:4898-4906.

11. Levy DE, Darnell JE Jr: Stats: transcriptional control and biological impact. Nat Rev Mol Cell Biol 2002, 3:651-662.

12. Calo V, Migliavacca M, Bazan V, et al: STAT proteins: from normal control of cellular events to tumorigenesis. J Cell Physiol 2003, 197:157-168.

13. O'Shea JJ, Pesu M, Borie DC, Changelian PS: A new modality for immunosuppression: targeting the JAK/STAT pathway. Nat Rev Drug Discov 2004, 3:555-564.

14. Santos SC, Lacronique V, Bouchaert I, et al: Constitutively active STAT5 variants induce growth and survival of hematopoietic cells through a PI 3-kinase/Akt dependent pathway. Oncogene 2001, 20:2080-2090.

15. Vidal OM, Stec W, Bausek N, et al: Negative regulation of Drosophila JAKSTAT signalling by endocytic trafficking. Cell Sci 2010, 9(14):723-729.

16. Lai SY, Johnson FM: Defining the role of the JAK-STAT pathway in head and neck and thoracic malignancies: implications for future therapeutic approaches. Drug Resist Updat 2010, 13(3):67-78.

17. Walker SR, Nelson EA, Zou L, et al: Reciprocal effects of STAT5 and STAT3 in breast cancer. Mol Cancer Res 2009, 7(6):966-976.

18. Sobti RC, Singh N, Hussain S, et al: Deregulation of STAT-5 isoforms in the development of HPV-mediated cervical carcinogenesis. Recept Signal Transduct Res 2010, 30(3):178-188.

19. Zhenjun Z, Lijie Z, Gang L, et al: siRNA targeting STAT5 induces apoptosis in human hepatocellular carcinoma cell line SMMC-7721. Transactions of the Third Military Medical University 2009, 31(12):1147-1150.

20. Zhao D, Zhu G, Xue X, et al: Influence of STAT5 siRNA on HeLa cell proliferation and apoptosis and its molecular mechanism. Chinese. Clin Oncol 2009, 14(10):879-883. 
21. Kureishy N, Sapountzi V, Prag S, Anilkumar N, Adams JC: Fascins and their roles in cell structure and function. Bioessays 2002, 24(4):350-361.

22. Ortiz CM, Tetsuo I, Yosuke H, Satoshi N, Akira I, Shigeru T, Fumiaki S, Miguel M, Jose G, Ana P, Yutaka S: Effects of small interfering RNAs targeting fascin on human esophageal squamous cell carcinoma cell lines. Diagn Pathol 2010, 5:41-51.

23. Koshiba $S, A n R$, Saito H, Wakabayashi $K$, Tamura A, Ishikawa T: Human ABC transporters ABCG2 (BCRP) and ABCG4. Xenobiotica 2008, 38:863-888.

24. Huang $Y$, Sadee $W$ : Membrane transporters and channels in chemoresistance and -sensitivity of tumor cells. Cancer Lett 2006, 239:168-182.

25. Huang L, Qiang L, Han Y, Li Z, Zhang Z, Xiaofei L: ABCG2/N-ATPase was associated with the drug resistance and tumor metastasis of esophageal squamous cancer cells. Diagn Pathol 2012, 7:180-187.

doi:10.1186/1746-1596-8-132

Cite this article as: Yang et al:: Effect of STAT5 silenced by siRNA on proliferation apoptosis and invasion of esophageal carcinoma cell line Eca-109. Diagnostic Pathology 2013 8:132.

\section{Submit your next manuscript to BioMed Central and take full advantage of:}

- Convenient online submission

- Thorough peer review

- No space constraints or color figure charges

- Immediate publication on acceptance

- Inclusion in PubMed, CAS, Scopus and Google Scholar

- Research which is freely available for redistribution 